\title{
Comparative study of anterior knee pain after patelloplasty with and without circumferential denervation in a total knee arthroplasty
}

\author{
Ahmed Latteef Al-Shamari, M.B.Ch.B, F.I.B.M.S.
}

\begin{abstract}
Background: The anterior knee pain is an important chief complaint of the patients with knee osteoarthritis due to patellofemoral pathology. The pain receptors denervation can be achieved by circumferential denervation of the patellar area by a process of electrocautery.

Objectives: The aim of current study is to assess the pain after total knee arthroplasty (TKA) by patelloplastywith and without circumferential denervation via electrocautery at a minimum follow up with 1 year separately for each patient.

Type of the study:Cross- sectional study.

Methods: Thirty five patients, with mean age of about (62.8) years, were enrolled in this prospective, hospital based study that was held at Al-Yarmouk Teaching Hospital in Baghdad from October 2012 to November 2016. These patients were divided into 2 groups, first group was composed of 19 patients who have TKA with patellar circumferential denervation by electrocautery with patelloplasty by removing peripheral osteophytes of patella , the second group of 16 patients were undergone TKA without denervation, but only patelloplasty. The second group was considered as the control group. Visual analogue scale (VAS) was used to evaluate pain pre and post operatively. The patient's functional ability was assessed by knee society score (KSS) also before and after TKA for both groups and pain killer was given according to patients need.
\end{abstract}

Results: All of the patients were followed for 12 months period. No drugs were used other than occasional use of pain killers in first month after operation for all patients in group one of study. On VAS scale, significant statistical difference in pre and post-operative scales were noticed between both groups of study. The Knee Society Scale (KSS) was showing a non- significant statistical significance between both study groups before and after TKA. ConclusionA: nterior knee pain can be reduced through the use of patelloplasty with circumferential denervation of patella byelectrocautery, compared with non- denervated procedure. Good clinical outcome was also present. Keywords: total knee arthroplasty, patellopasty, circumferential denervation, electrocautery, visual analogue scale and knee society score .

\section{Al-Kindy College Medical Journal 2017: Vol.13 No.2 Page: 106-110}

\author{
* M.B.Ch.B, F.I.B.M.S. College of Medicine/ Al- \\ Mustansiriya University
}

Received 26 $6^{\text {th }}$ April 2017, accepted in final $7^{\text {th }}$ June 2017 Corresponding to Ahmed Latteef Al-Shamari
T he increased incidence of osteoarthritis in many countries around the World made this disease as one of the major health problems in the present century (1). Among the common locations for osteoarthritis, the knee joint is considered as the most common site, with about half of patients over 50 years of age complaining from knee pain (2). Total knee arthroplasty (TKA) is one of the main surgical management for advanced cases of knee osteoarthritis. The Residual anterior knee pain after TKA is still considered as a problem of unclear mechanisms. The probable theory is the presence of many substance $P$ fibers in the area of patellar tissue and its surroundings, which is highly sensitive to pain stimuli (3). Although TKA is considered as a standard procedure carried for end stage degenerative disease of the knee joint, resurfacing of patella remain seeking for clarification in coordination with this procedure, with controversy among studies $(4,5)$. Meta-analyses studies have suggested non difference in anterior knee pain outcome between the studies of resurfaced and non-resurfaced patella in TKA (6). Generally, patelloplasty (removal of osteophytes) plus the senconv denervation of anterinr lateral and medial cutaneous nerve branches of patella by electrocautery of (fig. 1) without patellar resurfacing have been performed in TKA due to the easy implantation and the minimum need for additional surgical procedures (7).

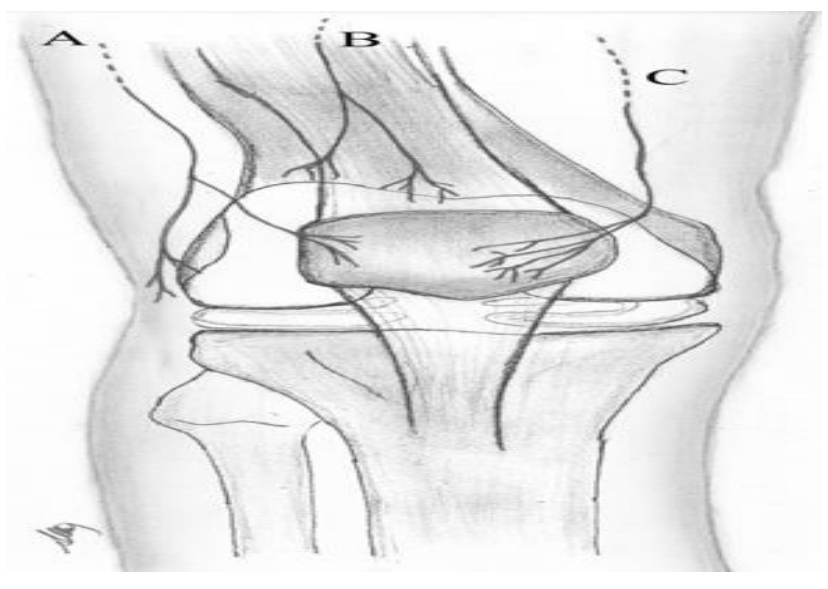

Figure (1): nerve supply around patellar region :(A) lateral cutaneous nerve of thigh, (B) anterior cutaneous nerve of thigh,(C) medial cutaneous nerve of thigh .

Many studies showed that when patellofemoral articulation was not taking in consideration as a pain source, symptoms of pain were recorded in up to $30 \%$ of cases even with the well performed arthroplasty $(8,9)$. 
Better results were noticed with patelloplasty compared to traditional total knee arthroplasty in regard to pain relief among patients followed- up for about 2 years (10). The aim of current study is to assess the anterior knee pain after patelloplastywith and and without cicumferentialdenervation during total knee arthroplasty.

Methods : A hospital based, prospectivecohort study was held on Al-Yarmouk Teaching Hospital in Baghdad from Oct 2012 to the end of November 2016, were 35 patients aged from 51 to 72 years old enrolled in this study. From these patients, 19 were involved as a first group whom undergone TKA withpatelloplastyand patellar circumferential denervation by electrocautery, while the other 16 patients were submitted to TKA without patellar circumferential denervation just patelloplasty. The second group was considered as a control group. Both groups were followed up for a minimum of 1 year. Operative procedure: midline skin incision with medial parapatellararthrotomy was done for the patients, then after finishing and apply definitive femoral and tibial implants, apatelloplasty was performed for both groups by removing peripheral osteophytes without resurfacing for both groups with electrocautery to a 2-3 millimeters of depth around patella for first group only according to clinical practice (fig. 2). Visual analogue scale (VAS) is used for pain evaluation for current study groups preoperatively, and also after 3, 6 and 12 months of the operation. Knee society score (KSS) is also used in current study for both groups to evaluate the patient's functional ability before and after TKA. Both T- test and Chi- square test were used for statistical analysis to compare between both groups of study. P- value less than 0.05 were considered significant.

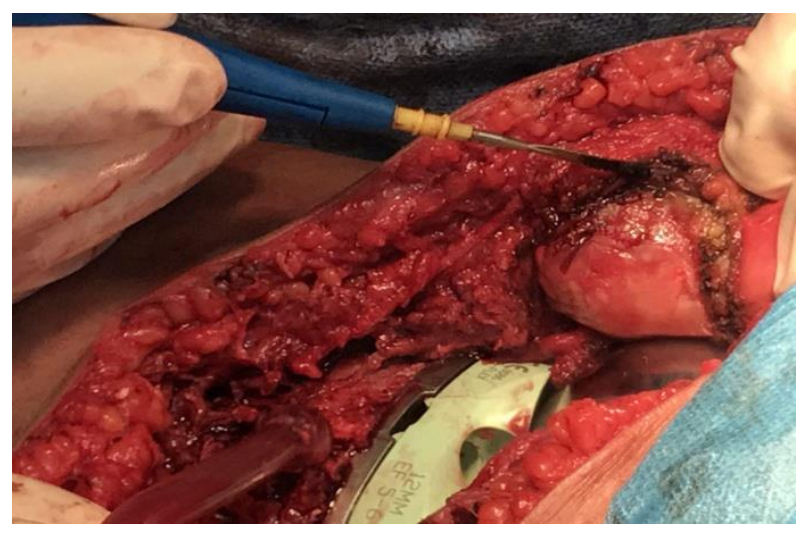

Figure (2): Total knee arthroplasty with patellar denervation

Results: Among 35 patients enrolled in this study, 21 were females and only 14 were males, their age groups were shown in table (1). The female to male ratio was (1.5: 1), and the mean class interval was about (62.8) years.

Table (1): The age distribution of current study patients

\begin{tabular}{|c|c|c|c|c|c|c|c|}
\hline \multirow[t]{2}{*}{ Age group } & \multicolumn{2}{|c|}{ Male } & \multicolumn{2}{|c|}{ female } & \multirow[t]{2}{*}{ Total } & \multirow[t]{2}{*}{ Percentage } & \multirow{2}{*}{$\begin{array}{c}\text { Mean class } \\
\text { interval }\end{array}$} \\
\hline & Group 1 & Group 2 & Group 1 & Group 2 & & & \\
\hline 50-59 years & 3 & 2 & 3 & 2 & 10 & $28.6 \%$ & \multirow{5}{*}{$\begin{array}{c}62.8 \\
\text { years }\end{array}$} \\
\hline 60-69 years & 4 & 3 & 7 & 7 & 21 & $60 \%$ & \\
\hline$\geq 70$ years & 1 & 1 & 1 & 1 & 4 & $11.4 \%$ & \\
\hline \multirow[t]{2}{*}{ Total } & 8 & 6 & 11 & 10 & \multirow[t]{2}{*}{35} & \multirow[t]{2}{*}{$100 \%$} & \\
\hline & \multicolumn{2}{|c|}{14} & \multicolumn{2}{|c|}{21} & & & \\
\hline
\end{tabular}

Visual analogue scale (VAS) was assessed for both groups. Table (2) shows the comparison between the means of both groups before TKA regarding this scale. A non- significant statistical difference was noticed $(P>0.05)$. Table $(3)$ shows the comparison between the means of both groups after 3 months of TKA regarding this scale. A non- significant statistical analysis $(P>0.05)$ was noticed. Table (4) shows the comparison between the means of both groups after 6 months of TKA regarding this scale. A significant statistical analysis $(P<0.05)$ was noticed.

Table (2): A comparison between study groups in current study regarding VAS before operation.

\begin{tabular}{|c|c|c|c|c|c|}
\hline Study group & $\begin{array}{c}\text { Mean VAS } \\
\pm \text { SD }\end{array}$ & T- test & S.E. & Confidence Interval & P-value \\
\hline \begin{tabular}{c|c|c|c|} 
Group 1 \\
$(\mathrm{n}=19)$
\end{tabular} & $8.6 \pm 1.2$ & 0.47 & 0.42 & $0.66-1.06$ & 0.64 \\
\cline { 1 - 2 } $\begin{array}{c}\text { Group 2 } \\
(\mathrm{n}=16)\end{array}$ & $8.4 \pm 1.3$ & & & \\
\hline
\end{tabular}


Table (3): A comparison between study groups in current study regarding VAS after 3 months of operation.

\begin{tabular}{|c|c|c|c|c|c|}
\hline Study group & $\begin{array}{c}\text { Mean VAS } \\
\pm \text { SD }\end{array}$ & T- test & S.E. & Confidence Interval & P-value \\
\hline $\begin{array}{c}\text { Group 1 } \\
(n=19)\end{array}$ & $7.1 \pm 1.5$ & 0.4 & 0.49 & $0.8-1.2$ & 0.69 \\
\hline $\begin{array}{c}\text { Group 2 } \\
(n=16)\end{array}$ & $7.3 \pm 1.4$ & & & \\
\hline
\end{tabular}

Table (4): A comparison between study groups in current study regarding VAS after 6 months of operation.

\begin{tabular}{|c|c|c|c|c|c|}
\hline Study group & $\begin{array}{c}\text { Mean VAS } \\
\pm \text { SD }\end{array}$ & T- test & S.E. & Confidence Interval & P-value \\
\hline $\begin{array}{c}\text { Group 1 } \\
(n=19)\end{array}$ & $5.9 \pm 0.7$ & 2.22 & 0.27 & $0.05-1.15$ & $0.034^{*}$ \\
\hline $\begin{array}{c}\text { Group 2 } \\
(n=16)\end{array}$ & $6.5 \pm 0.9$ & & & \\
\hline
\end{tabular}

* Significant

Table (5) shows the comparison between the means of both groups after one year of TKA regarding this scale. A significant statistical analysis $(\mathrm{P}<0.05)$ was noticed.

Table (5): A comparison between study groups in current study regarding VAS after 1 year of operation.

\begin{tabular}{|c|c|c|c|c|c|}
\hline Study group & $\begin{array}{c}\text { Mean VAS } \\
\pm S D\end{array}$ & T- test & S.E. & Confidence Interval & P-value \\
\cline { 1 - 2 } $\begin{array}{c}\text { Group 1 } \\
(n=19)\end{array}$ & $3.7 \pm 0.8$ & 8.5 & 0.27 & $1.74-2.85$ & $<0.01^{*}$ \\
\cline { 1 - 2 } $\begin{array}{c}\text { Group 2 } \\
(n=16)\end{array}$ & $6 \pm 0.8$ & & & & \\
\hline
\end{tabular}

${ }^{*}$ Highly significant

Knee society score (KSS) was evaluated for both groups before the operation, as shown in Table (6). Non- significant statistical analysis was noticed between both groups.

Table (6): A comparison between study groups in current study regarding KSS before TKA operation.

\begin{tabular}{|c|c|c|c|c|c|}
\hline Study group & $\begin{array}{c}\text { Mean KSS } \\
\pm S D\end{array}$ & T- test & S.E. & Confidence Interval & P-value \\
\hline $\begin{array}{c}\text { Group 1 } \\
(n=19)\end{array}$ & $49 \pm 6$ & 0.91 & 2.19 & $2.47-6.47$ & 0.37 \\
\cline { 1 - 2 } $\begin{array}{c}\text { Group 2 } \\
(n=16)\end{array}$ & $47 \pm 7$ & & & & \\
\hline
\end{tabular}

Table (7) shows the comparison between both groups in regard to KSS after one year of the operation. Non- Significant statistical analysis $(P>0.05)$ was noticed. 
Table (7): A comparison between study groups in current study regarding KSS after 1 year of TKA.

\begin{tabular}{|c|c|c|c|c|c|}
\hline Study group & $\begin{array}{c}\text { Mean KSS } \\
\pm \text { SD }\end{array}$ & T- test & S.E. & Confidence Interval & P-value \\
\hline $\begin{array}{c}\text { Group 1 } \\
(n=19)\end{array}$ & $92 \pm 4$ & 1.97 & 1.52 & $0.09-6.09$ & 0.057 \\
\hline $\begin{array}{c}\text { Group 2 } \\
(n=16)\end{array}$ & $89 \pm 5$ & & & \\
\hline
\end{tabular}

Discussion : Anterior knee pain is one of the common complications of TKA operation that is estimated to be seen in half of the patients, and its relation to resurfacing of the patella remains a controversial issue in orthopedic. Authors found that circumferential denervation technique- which is a standard methodprovides little difference in outcome regarding the anterior knee pain compared with that after patellar resurfacing in TKA (11). In current study groups, the mean age of patientswas about 62.8 years old. Females were more than males, with $(1.5: 1)$ ratio. This goes with many studies who revealed that females constituted $2 / 3$ of cases, with mean age of more than 60 years of age $(4,7,10$, and 11). Both groups were of nearly the same pain scale (i.e. VAS) before TKA, with non significant statistical difference between them. After 3 months of the operation, both groups were showing a slight decrease in VAS compared with that before TKA, with a non-significant statistical difference between them. This is due to the fact that in early period after TKA, the wound healing is notcomplete, leading to the slight VAS changes andthe non- significant difference between both study groups.It is worthwhile here to emphasize on wound healing problems which should be avoided during this period with the special and aggressive care, as the minimal incision infection can turn into a major complication (12). After 6 months of TKA, significant statistical difference $(P<0.05)$ was seen, and group (1) patients were more satisfied with progressive pain decrease. This was even better after one year of the operation, and highly significant statistical difference $(P<0.01)$ was noticed between both study groups. This agrees with many studies around the world $(13,14$, and 15) which showed the beneficial effect of patellar denervation against non- patellar denervation procedure. Regarding the knee society score (KSS), current study showed a non-significant statistical difference between study groups before and after one year of the operation. This agrees with Pulavarti et al (16) who noticed same results regarding $\mathrm{KSS}$, as multifactorial interference regarding the knee function is a well- established fact that can affect the score (7). One of the limitations of current study is short duration of patients follow and less cases in comparisom with other studies due to general circumstances of patients, some of them disappear during follow up and not every patient accept idea of undergoing to such a major surgery .
Conclusion: The anterior knee pain in TKA accompanied with patelloplasty can be reduced specially if associated with patellar denervation via electrocauteryif compared with no patellar denervation.

\section{References}

1. World Health Organization Scientific Group. The burden of musculoskeletal conditions at the start of the new millennium. World Health Organization, Geneva2003.Availablefrom URL:https://www.ncbi.nlm.nih.gov/pubmed/146 79827.

2. Van der Waal JM, Terwee CB, and Van der Windt. Health- related and overall quality of life of patients with chronic hip and knee complaints in general practice. Quality of life research 2005; 14: 795-803.

3. Dye SF. The pathophysiology of patellofemoral pain; a tissue hemostasis perspective. Clinical orthopedic relative research 2005; 436: 100 110.

4. Smith AJ, wood DJ, Li MG. total knee replacement with and without patellar resurfacing. The journal of bone and joint surgery 2008; 90B(1):43- 49.

5. Sreehari CK, Nithin S. patellar resurfacing compared with non- resurfacing in total arthroplasty: a 5- year follow- up study. OA orthopedics 2014; 2 (2): 13.

6. Calvisi V, camillieri G, and luparelli $\mathrm{S}$. Resurfacing versus non- resurfacing the patella in total knee arthroplasty: a critical appraisal of the available evidence. Arch orthopedic trauma surgery 2009; 129: 1261- 1270.

7. Altay MA, Erturk $\mathrm{C}$, Altay $\mathrm{N}$, et al. patellar denervation in total knee arthroplasty without patellar resurfacing: A prospective randomized controlled study. Orthopedics and Traumatology Surgical Researches 2012;98(4):421- 425.

8. Peng CW, Tay BK, Lee BP. Prospective trial of resurfaced patella versus non resurfaced

9. patella in simultaneous bilateral total knee replacement. Singapore medical journal 2003; 44: 347 - 351. 
10. Smith AJ, Wood DJ, Li MG. total knee replacement with and without patellar resurfacing: a prospective, randomized trial using the profix total knee system. Journal of bone and joint surgery of Britain 2008; 90: 4349.

11. Sun $Y Q$, Yang B, Tong SL, et al. patelloplasty versus traditional total knee arthroplasty for osteoarthritis. Orthopedics 2012; 35 (3): e343e348.

12. Spencer BA, Cherian JJ, Margetas G, et al. Patellar resurfacing versus circumferential denervation of the patella in total knee arthroplasty. Tips and Technique 2016; 39 (5): e1019-e1023.
13. Garbedian S, Sternheim A, Backstein D. Wound healing problems in total knee arthroplasty. Orthopedics 2011; 34 (9): e516518.

14. Badhe N, Dewnany G, Livesley PJ. Should the patella be replaced in total knee replacement? International Orthopedics 2001; (2):97- 99.

15. Yim SJ, Jang MS, Kim WJ, et al. The Effect of Electrocautery around the Patellar Rim in Patellar Non-Resurfacing Total Knee Arthroplasty. Knee Surgery Related Research 2012; 24(2): 104- 107.

16. Feller JA, Bartlett RJ, Lang DM. Patellar resurfacing versus retention in total knee arthroplasty. The Journal of Bone and Joint Surgery- British volume 1996;78(2):226- 228.

17. Pulavarti RS, Raut VV, McLauchlan GJ. Patella denervation in primary total knee arthroplasty a randomized controlled trial with 2 years of follow-up. Journal of Arthroplasty 2014;29(5):977- 981. 